ORIGINAL ARTICLE

\title{
Phosphodiesterase inhibitors in vascular ischemia: A case report and review of their use in ischemic conditions
}

\author{
Wendy KY Ng MD ${ }^{1,2}$, Yishai Rosenblatt MD ${ }^{1,2}$, Gerald B Brock MD FRCSC ${ }^{2,3,4}$, \\ David B O'Gorman MSc PhD1,2,4,5,6, Bing Siang Gan MD PhD FRCSC FACS 1,2,4,6,7,8
}

\begin{abstract}
WKY Ng, Y Rosenblatt, GB Brock, DB O'Gorman, BS Gan. Phosphodiesterase inhibitors in vascular ischemia: A case report and review of their use in ischemic conditions. Can J Plast Surg 2010;18(1):e5-e9.

The treatment of digital ischemia remains difficult. Sildenafil (Viagra, Pfizer UK), a selective phosphodiesterase inhibitor, increases blood flow and is currently marketed for the treatment of erectile dysfunction. A case of a 57-year-old man with progressive episodic ischemia and pain of the fingertips resulting in finger tip ulceration is presented. After failure of medical and surgical management, a trial of oral sildenafil resulted in marked symptomatic improvement of his bilateral digital ischemia. Review of the literature shows that, particularly in patients with an underlying disease such as scleroderma with a vasospastic component, a marked improvement in digital blood flow may be observed with sildenafil use. Overall, based on a number of case reports and preliminary animal studies in the literature, sildenafil appears to have a growing significance in the treatment of hand ischemia. Similarly, there is evidence that phosphodiesterase 5 inhibitors may be used as an adjunct to improving skin flap survival.
\end{abstract}

Key Words: Digital ischemia; Phosphodiesterase inhibitors (PDE inhibitors); Sildenafil; Skin flap survival

Tschemia of the hand remains difficult to treat, particularly in 1 patients with an underlying vasospastic or collagen vascular disorder. The role of surgery has traditionally been limited to more severe conditions involving critical ischemia. Surgical procedures in these patients may consist of vascular or microvascular bypass surgery, proximal and distal sympathectomy and often, unfortunately, revision amputation (1).

Phosphodiesterase (PDE) inhibitors, such as sildenafil (Viagra, Pfizer UK), act by relaxing constricted blood vessels via inhibition of the enzyme that is involved in maintaining proper blood vessel tone. PDE inhibitors increase the concentration of vasodilating mediators, resulting in increased blood flow. This class of drugs has been approved for the treatment of erectile dysfunction; however, off-label use extends to disorders in which vasodilation can confer therapeutic benefits. Such conditions include primary pulmonary hypertension (2), as well as learning and memory processes associated with aging $(3,4)$.

In the present article, the successful use of a PDE inhibitor in a patient presenting with ischemia of the hand is described, and the evidence about this class of drugs in other conditions such as Raynaud's disease and systemic sclerosis (scleroderma) is reviewed. The potential benefits of PDE inhibitors in skin flap survival and minimization of ischemic necrosis, as
Les inhibiteurs de la phosphodiestérase en présence d'ischémie vasculaire : Un rapport de cas et une analyse de leur utilisation en cas de maladies ischémiques

L'ischémie digitale demeure difficile à traiter. Le sildénafil (Viagra, Pfizer, Royaume-Uni), un inhibiteur sélectif de la phosphodiestérase qui accroît le débit sanguin, est en marché pour le traitement de la dysfonction érectile. Est présenté le cas d'un homme de 57 ans ayant une ischémie épisodique évolutive et une douleur au bout des doigts provoquant des ulcérations. Après l'échec de la prise en charge médicale et chirurgicale, l'essai du sildénafil par voie orale a favorisé l'amélioration symptomatique marquée de l'ischémie digitale bilatérale. L'analyse bibliographique démontre que, surtout chez les patients ayant une maladie sous-jacente comme une sclérodermie comportant un volet vasospastique, on peut observer une amélioration du débit sanguin vers les doigts grâce au sildénafil. Dans l'ensemble, selon le nombre de rapports de cas et d'études préliminaires sur des animaux contenu dans les publications, le sildénafil semble avoir une importance croissante dans le traitement de l'ischémie de la main. De même, des données probantes indiquent que les inhibiteurs de la phosphodiestérase de type 5 peuvent être utilisés comme traitement d'appoint pour améliorer la survie des lambeaux cutanés.

demonstrated by a number of preliminary animal studies, are also reviewed.

\section{CASE PRESENTATION}

A right-handed 57-year-old baker presented with episodes of a painful, swollen, left index finger associated with purple discolouration of the fingertip (Figures 1 and 2). The intensity of the pain fluctuated during the day, at times becoming excrutiating. Workup revealed no proximal arterial obstruction or possible source of obstructing emboli, and no other underlying systemic illness. Doppler studies (pre- and postmetacarpal block anesthesia) revealed a spastic vasoconstrictive component. A diagnosis of primary Raynaud's disease was made.

The patient was started on a trial of nifedipine PA (Adalat, Bayer Schering Pharma, Germany) at a dose of $10 \mathrm{mg}$ taken orally, twice a day, to relieve vasospasm, $81 \mathrm{mg}$ of acetylsalicylic acid (ASA) to reduce platelet aggregation, and hydromorphone (Percocet, Endo Pharmaceuticals, USA) for pain. However, after two weeks, there was no relief of symptoms, and ischemic ulceration of the fingertips appeared. The patient was then referred for digital microscopic sympathectomy. Two days following sympathectomy, his pain, discolouration and decreased digital temperature had markedly improved, although he experienced mild neuropraxia. He was started on a course of

${ }^{1}$ The Hand and Upper Limb Centre; ${ }^{2}$ Schulich School of Medicine and Dentistry; ${ }^{3}$ Division of Urology; ${ }^{4}$ Department of Surgery; ${ }^{5}$ Department of

Biochemistry; ${ }^{6}$ Division of Plastic Surgery; ${ }^{7}$ Division of Physiology and Pharmacology; ${ }^{8}$ Department of Medical Biophysics, The University of

Western Ontario, London, Ontario

Correspondence: Dr Bing Siang Gan, The Hand and Upper Limb Centre, 268 Grosvenor Street, London, Ontario N6A 4L6.

Telephone 519-646-6097, fax 519-646-6049, e-mail bsgan@rogers.com 


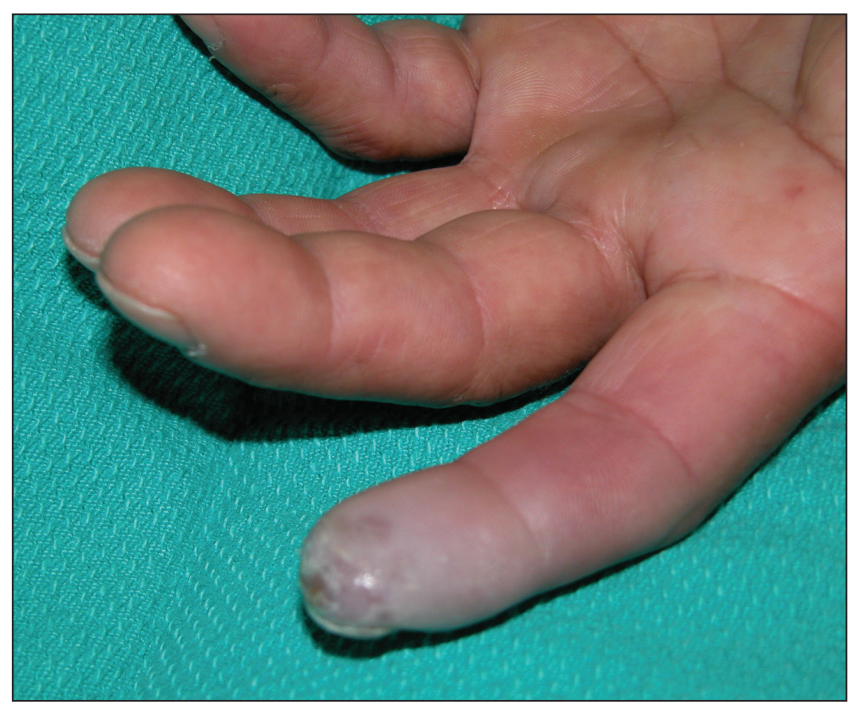

Figure 1) Clinical photograph of the ischemic distal index finger

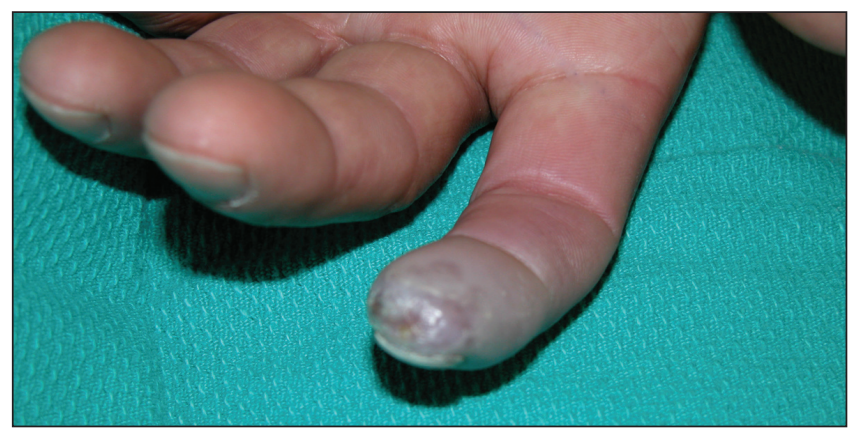

Figure 2) Clinical photograph of the ischemic index finger

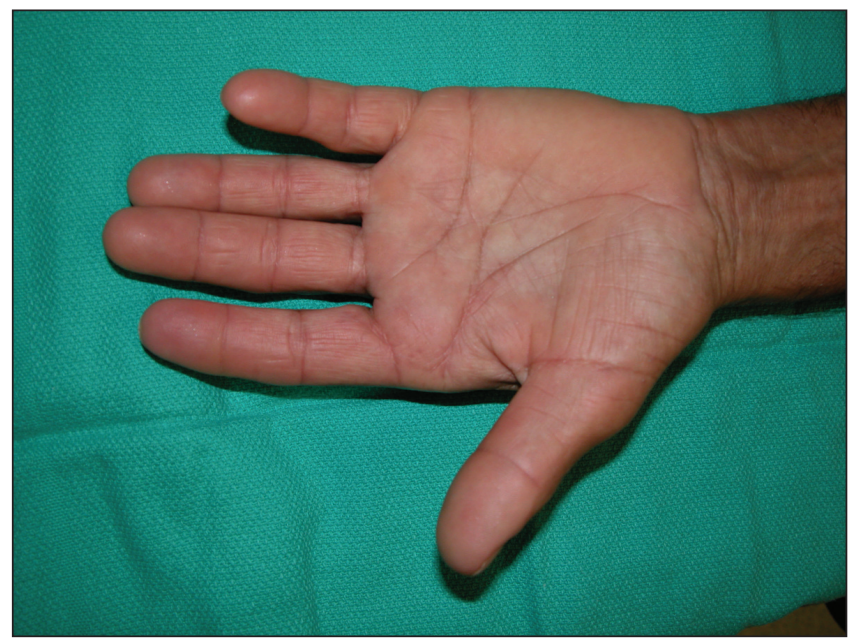

Figure 3) Reperfused index finger within seven days following initiation of treatment with oral sildenafil

physiotherapy to regain range of motion. Unfortunately, by the 10th postoperative day, his symptoms relapsed. ASA administration was increased to $325 \mathrm{mg}$ daily, and nitropaste ointment $2 \%$ was applied twice a day to the base of the index finger. Within two weeks, the finger appeared pink and warm, with improved capillary refill. Ulcers at the tip of his finger completely healed. Four months following surgery and without further nitropaste application, the patient was symptom free and was discharged on ASA and nifedipine. However, one year following his initial presentation, the patient noted an increasing sensation of coldness with blue discolouration, this time affecting all digits of both hands. There was a small ulceration on the tip of his right ring finger. Nifedipine was increased to $10 \mathrm{mg}$ taken orally three times a day, and pentoxifylline (Trental, sanofi-aventis US) $400 \mathrm{mg}$ taken orally, twice a day, was added. However, following three additional weeks of medical treatment, the patient noted no change and his pain remained severe.

Rather than advocating bilateral multidigit sympathectomy, a trial of sildenafil (Viagra) at $50 \mathrm{mg}$ taken orally, once daily, was started. Within hours of first administration, his pain and ischemic symptoms disappeared (Figure 3). Three months later, he remained symptom free on this dose of sildenafil (Viagra) without reported side effects. Unfortunately, the insurance company denied the patient reimbursement for the medication - the patient was forced to discontinue the drug. Within one week, the pain returned and the medication was restarted with excellent pain relief. The patient remains symptom free while on the drug, but has experienced recurrence of pain when he runs out of medication. The drug is now provided by the manufacturer on compassionate grounds.

\section{DISCUSSION}

Ischemia of the distal extremities remains difficult to treat. Currently, the mainstay of management of this entity consists of ruling out proximal arterial obstruction or arterial emboli through ultrasound, angiography and/or echography. Further medical workup may include an autoimmune screening panel to rule out underlying collagen vascular disorders and or vasculitis. A workup to differentiate between structural obstruction and vasospasm may consist of digital Doppler plethysmography before and after administration of a pharmacological sympathetectomy by metacarpal block anesthesia (5).

Primary treatment is usually aimed at concomitant disease, which may contribute to the ischemia, such as scleroderma or vasculitis (6). Lifestyle modification including smoking cessation, abstinence from caffeine and other vasoconstricting agents should be instituted. Symptomatic relief may be obtained with vasodilating agents including calcium antagonists, topical nitrate application, and agents that may improve hemorheology such as ASA, pentoxifylline (Trental) or even full systemic anticoagulation. The latter may also be helpful in cases of suspected embolic events resulting from, for example, atrial fibrillation. ASA and pentoxifylline and its metabolites improve the flow properties of blood by decreasing its viscosity. In patients with chronic peripheral arterial disease, this increases blood flow to the affected microcirculation and enhances tissue oxygenation.

In cases with proximal vascular obstruction, surgical bypass may be helpful and, in extreme cases without clear cause, surgical management may consist of sympathectomy. The latter can be performed at various levels including proximal (eg, brachial plexus) or distal, such as at the level of the metacarpals $(5,7)$. However, despite combination treatment, ischemia can be irreversible, causing necrosis of the tips of the digits and a possible requirement for revision amputation. Nonetheless, because healing is often compromised in these cases, most surgeons advocate a conservative approach (8). 


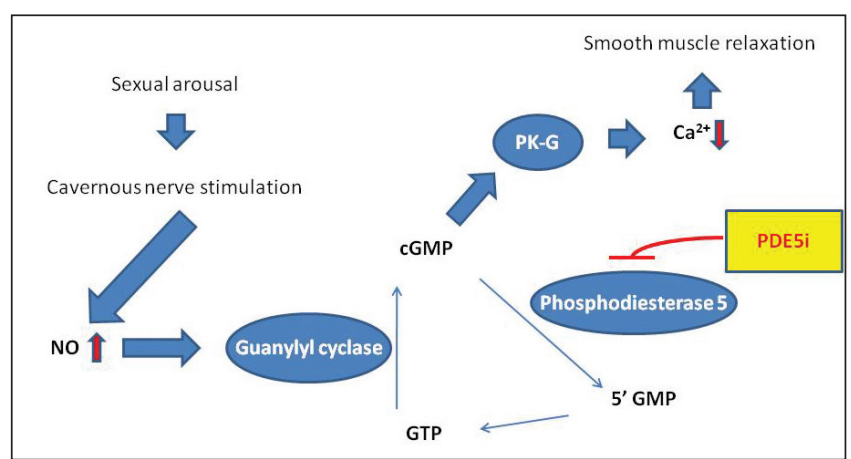

Figure 4) Phosphodiesterase 5 (PDE5) in penile erection. Sexual arousal results in stimulation of the cavernous nerves with synthesis of nitric oxide (NO) by neuronal NO synthase. NO stimulates guanylyl cyclase-converting GTP to cyclic GMP (cGMP). cGMP activates protein kinase $\mathrm{G}$ (PK-G), which results in sequestration of $\mathrm{Ca}^{2+}$ and subsequent smooth muscle relaxation and erection. Detumescence occurs when CGMP is metabolized to 5' GMP by the enzyme PDE5, resulting in inactivation of PK-G. The PDE5 inhibitor (PDE5i) inhibits conversion of cGMP to 5' GMP and, thus, results in prolonged activation of $\mathrm{PK}-\mathrm{G}$ and potentiation of erection. Endothelial NO synthase also plays a role in erection, but for simplification has not been included in the figure

The present case illustrates the difficulties associated with digital ischemia with a recurrent relapsing clinical picture and inability to control symptoms with a multipronged conventional approach. In the end, because of the widespread vasospastic picture that the patient exhibited, an alternative medication was used to achieve vasodilation.

Sildenafil (Viagra) is a synthetic PDE inhibitor currently approved for the treatment of erectile dysfunction (9). Using this medication, pain and other ischemic conditions were controlled in a variety of patients who had no clear underlying illness. However, a number of patients with digital ischemia resulting from concomitant illness, such as scleroderma with resultant intractable pain, were also treated. In several patients, after institution of sildenafil, revision amputation of already irreversibly ischemic fingertips was performed, without any subsequent wound healing problems. Because the advent of PDE inhibitors has largely occurred outside of the direct scope of plastic surgery, some of the evidence that documents the possible benefits of the use of this class of medication in our specialty will be reviewed.

Mechanism of action and systemic effects of PDE inhibitors There are 11 isoenzymes of PDE, with different distributions throughout the body (10). In particular, PDE type 5 (PDE5) is located in vascular tissue such as blood vessels, platelets and vascular smooth muscle. Pfizer in the United Kingdom originally developed sildenafil with the intent of augmenting the nitric oxide (NO)/ cyclic GMP (cGMP) pathway for the treatment of angina pectoris in coronary artery disease patients (11). In clinical trials, the effects on patients with a vascular component to erectile dysfunction became evident. Since then, three specific PDE5 inhibitors (sildenafil [Viagra], vardenafil [Levitra, Bayer Inc, Canada] and tadalafil [Cialis, Lilly USA LLC]) have been approved by the United States Food and

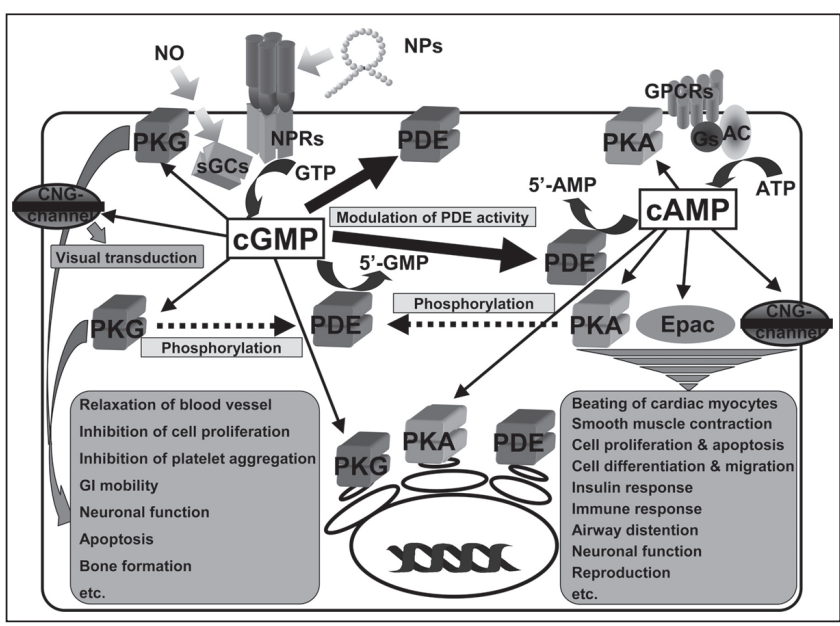

Figure 5) Complete diagram of phosphodiesterase (PDE) effects in humans. Localization of the fundamental molecules involved in adenosine 3',5'-cyclic monophosphate (cAMP) and cyclic GMP (cGMP) signalling and their effects are illustrated. Effector molecules of cAMP and cGMP are indicated by arrows from each cyclic nucleotide. Phosphorylation of PDEs by protein kinase A (PKA) and protein kinase $G(P K G)$ is demonstrated by dotted arrows. Modulation of PDE activity by cGMP is shown by a thick arrow. Cellular and physiological outputs of cyclic nucleotide signalling are shown in gray-coloured boxes. AC Adenylyl cyclase; CNG-channel Cyclic nucleotide-gated channel; Epac Exchange protein directly activated by cAMP; GI Gastrointestinal; GPCRs G proteincoupled receptors; Gs GTP-binding protein subunit; NO Nitric oxide; NPs Natriuretic peptides; NPRs Natriuretic peptide receptors; sGCs Soluble guanylyl cyclase. Reproduced with permission from reference 10

Drug Administration for treatment of erectile dysfunction (12), and have become blockbuster drugs with annual sales in the $\$ 3$ billion range.

In the penis (and presumably in other vascular tissues), vascular smooth muscle relaxes through the synthesis of $\mathrm{NO}$ (Figure 4). Erection begins with neural stimulation from the cavernous nerves, which releases $\mathrm{NO}$ and induces an increase in cGMP, leading to activation of protein kinase $G$ (PKG). PKG phosphorylates proteins that regulate corporal smooth muscle tone by regulating $\mathrm{Ca}^{2+}$ sequestration. $\mathrm{Ca}^{2+}$ sequestration results in smooth muscle relaxation and increased vascular flow. PDEs play a key role in the physiology of erection because these enzymes hydrolyze both cGMP and adenosine 3',5'-cyclic monophosphate. Isoforms PDE2, 3, 4 and 5 appear to be the dominant isoforms in the corpus cavernosum. Selective inhibition of PDE5 prevents the breakdown of cGMP, thus promoting the corpus cavernosum smooth muscle to relax, and potentiating erections during sexual stimulation (13). Many of the other effects of the members of the PDE family of enzymes have now been documented, and intersection with other second messenger systems has also been delineated (Figure 5).

The use of PDE5 inhibitors has been expanding in many areas since their introduction. Systemic effects of PDE5 inhibitors include reducing pulmonary systolic and diastolic arterial pressures and arteriolar resistance, both arteriodilating and venodilating properties on peripheral vasculature, antiaggregatory effects on 
platelets, induction of smooth muscle relaxation and inhibition of peristalsis by NO-mediated cGMP pathways. There is an unclear effect on cardiac contractility. Long-term chronic use of PDE5 inhibitors thus offers beneficial pulmonary and cardiac effects (14). Its effects on blood flow are noticeable in the alleviation of disorders associated with decreased blood flow. As a result, in addition to its established role in the treatment of erectile dysfunction, these drugs have been used successfully for other conditions, such as primary and secondary pulmonary hypertension, congestive heart failure and diabetic neuropathy $(11,15-17)$. There is also mounting evidence that sildenafil may be beneficial in the treatment of Raynaud's phenomenon, joint stiffness and fibrosis in systemic sclerosis, and digital ischemia (18-20).

Predictable adverse effects occur in approximately $20 \%$ of patients including headache, nasal congestion and flushing (21). Rarely, sildenafil use may result in vision loss (22-23). The drug is contraindicated in patients taking nitrates, due to potential hypotension. Relative contraindications to the use of PDE5 inhibitors include alpha-blockers and antihypertensive medications. The concurrent use of potent cytochrome P450-3A4 inhibitors (such as erythromycin, ketoconazole or itraconazole) or the nonspecific CYP inhibitor, cimetidine, has been associated with increased plasma levels of PDE5 inhibitors; however, the clinical relevance of these observations remains controversial (11). A recent review (24) on the effects of sildenafil on fatal cardiac events seem to indicate that sildenafil, in fact, may confer a protective effect in the absence of coadministration with alpha-blockers or NO donors.

\section{PDE5 inhibitors and peripheral ischemia}

It has been suggested that PDE5 inhibitors may be appropriate in patients with severe symptoms associated with Raynaud's disease when traditional vasodilator therapy has failed (25). Mean frequency of Raynaud's attacks was lower, cumulative attack duration was shorter, and mean capillary flow velocity was improved after sildenafil (15) and alprostadil treatment (26). In a group of patients with Raynaud's phenomenon associated with systemic sclerosis, use of sildenafil resulted in a reduced frequency and severity of Raynaud's attacks, and 75\% of patients who had digital ulcers refractory to conventional treatment experienced complete ulcer healing. The patients who did not experience ulcer healing with sildenafil were believed to have fibrosis or occlusion of vessels that did not allow greater vasodilation (27). In a patient with chemotherapy-induced Raynaud's phenomenon, tadalafil was effective in treating these ischemic symptoms (28).

In a small group of patients with autoimmune disease and progressively severe digital ischemia despite treatment with various other medications, sildenafil provided immediate subjective and objective improvements, such as improved digital circulation and pain, extremities becoming warm and less discoloured, or healing of toe ulcers. Interestingly, in several patients, worsening Raynaud's phenomenon and digital ischemia occurred after the initiation of antituberculosis chemotherapy. It was noted that rifampicin, which enhances sildenafil elimination through induction of P450 enzymes, worsened outcome and led to rapid development of digital gangrene (29), suggesting that PDE5 inhibition did indeed confer a vasodilating effect.
Suggested doses in various clinical studies $(15,25)$ that exhibit beneficial activity of PDE inhibitors include sildenafil (Viagra) $50 \mathrm{mg}$ twice daily, vardenafil (Levitra) $10 \mathrm{mg}$ twice daily, and tadalafil (Cialis) $20 \mathrm{mg}$ every two to three days, although further studies are needed to delineate optimal dosing suggestions. Other doses that have been examined in clinical human studies include starting doses of sildenafil (Viagra) ranging from $12.5 \mathrm{mg} /$ day to $100 \mathrm{mg} /$ day in single or divided doses (20,26-29). The patient described in the present study was weaned to a $50 \mathrm{mg}$ dose every three days, which is the lowest dose and longest interval that seems to be effective in this patient.

\section{Sildenafil in ischemic animal studies}

Over the past few years, sildenafil has also been studied in animal models to determine its efficacy in minimizing ischemia and promoting skin flap survival. In a mouse hind limb ischemia model, sildenafil significantly increased vascular perfusion, tissue blood flow and vascular density, as measured by angiography, laser Doppler techniques and change in immunological markers (16). The sildenafil-mediated angiogenic activity was blocked by inhibition of PKG using the PKG antagonist, DT3. PKG is an important mediator of ischemia-induced angiogenesis, suggesting that sildenafil enhances ischemia-induced angiogenesis through a PKGrelated pathway (16).

Using a rat dorsal random-pattern skin flap, administration of sildenafil in fibrin glue resulted in a significant decrease in flap necrosis, suggesting that topical sildenafil application improves flap survival in rat models (30). In a similar study (31), distally based dorsal skin flaps investigating sildenafil showed dose-dependent effects on random flap survival in rats, with higher doses and shorter intervals increasing efficacy. When examining the combined effects of sildenafil and vascular endothelial growth factor, the group receiving sildenafil and vascular endothelial growth factor in combination was not significantly different from the group of rats treated with sildenafil only, suggesting that the enhanced flap survival was only due to the effect of sildenafil (32). Timing of the beneficial effects of sildenafil has also been studied; administration of sildenafil may be more important in early rather than later postoperative skin flap viability (33).

Aside from sildenafil, other PDE5 inhibitors may also offer flap survival benefits. Tadalafil has similarly shown increased skin flap survival, as well as vasodilation of the choke vessels between adjacent angiosomes and formation of true anastomoses (34).

Overall, these animal studies appear to provide mounting evidence that PDE5 inhibitors improve survival of skin flaps, decrease comparative skin flap necrosis, and may be more valuable in terms of efficacy as early rather than later treatment.

\section{SUMMARY}

The benefits of PDE5 inhibitors have been examined in patients with Raynaud's phenomenon and with scleroderma. From the currently available literature, it appears that PDE5 inhibitors can play a role in the management of these disorders. In addition, it appears that there are possible advantages of PDE5 inhibitors in minimizing skin flap necrosis and combating extremity and flap ischemia. We hope that the present article promotes further studies of the emerging role for PDE5 
inhibitors in the treatment of digital ischemia. Such studies may be able to outline optimal dosing requirements and the possible mechanisms and indications for this class of drugs.

\section{REFERENCES}

1. McLafferty RB, Edwards JM, Taylor LM Jr, Porter JM. Diagnosis and long-term clinical outcome in patients diagnosed with hand ischemia. J Vasc Surg 1995;22:361-7; discussion 367-9.

2. Croom KF, Curran MP. Sildenafil: A review of its use in pulmonary arterial hypertension. Drugs 2008;68:383-97.

3. Domek-Lopacinska K, Strosznajder JB. The effect of selective inhibition of cyclic GMP hydrolyzing phosphodiesterases 2 and 5 on learning and memory processes and nitric oxide synthase activity in brain during aging. Brain Res 2008;1216:68-77.

4. Reneerkens OA, Rutten K, Steinbusch HW, Blokland A, Prickaerts J. Selective phosphodiesterase inhibitors: A promising target for cognition enhancement. Psychopharmacology (Berl) 2009;202:419-43

5. Ruch DS, Holden M, Smith BP, Smith TL, Koman LA. Periarterial sympathectomy in scleroderma patients: Intermediate-term follow-up. J Hand Surg Am 2002;27:258-64.

6. Herrick A. Diagnosis and management of scleroderma peripheral vascular disease. Rheum Dis Clin North Am 2008;34:89-114;vii.

7. Bogoch ER, Gross DK. Surgery of the hand in patients with systemic sclerosis: Outcomes and considerations. J Rheumatol 2005;32:642-8.

8. Kotsis SV, Chung KC. A systematic review of the outcomes of digital sympathectomy for treatment of chronic digital ischemia. J Rheumatol 2003;30:1788-92.

9. Sharma R. Novel phosphodiesterase-5 inhibitors: Current indications and future directions. Indian J Med Sci 2007;61:667-79.

10. Omori K, Kotera J. Overview of PDEs and their regulation. Circ Res 2007;100:309-27.

11. Schwarz ER, Kapur V, Rodriguez J, Rastogi S, Rosanio S. The effects of chronic phosphodiesterase-5 inhibitor use on different organ systems. Int J Impot Res 2007;19:139-48.

12. Mirone V, Fusco F, Rossi A, Sicuteri R, Montorsi F. Tadalafil and vardenafil vs sildenafil: A review of patient-preference studies. BJU Int 2009;103:1212-7.

13. Lue TF. Erectile dysfunction. N Engl J Med 2000;342:1802-13.

14. Kass DA, Champion HC, Beavo JA. Phosphodiesterase type 5: Expanding roles in cardiovascular regulation. Circ Res 2007;101:1084-95.

15. Fries R, Shariat K, von Wilmowsky H, Bohm M. Sildenafil in the treatment of Raynaud's phenomenon resistant to vasodilatory therapy. Circulation 2005;112:2980-5.

16. Senthilkumar A, Smith RD, Khitha J, et al. Sildenafil promotes ischemia-induced angiogenesis through a PKG-dependent pathway. Arterioscler Thromb Vasc Biol 2007;27:1947-54.
17. Kapur V, Chien CV, Fuess JE, Schwarz ER. The relationship between erectile dysfunction and cardiovascular disease. Part II: The role of PDE-5 inhibition in sexual dysfunction and cardiovascular disease. Rev Cardiovasc Med 2008;9:187-95.

18. Heymann WR. Sildenafil for the treatment of Raynaud's phenomenon. J Am Acad Dermatol 2006;55:501-2.

19. Yung A, Reay N, Goodfield MD. Improvement in digital flexibility and dexterity following ingestion of sildenafil citrate (viagra) in limited systemic sclerosis. Arch Dermatol 2005;141:831-3.

20. Colglazier CL, Sutej PG, O'Rourke KS. Severe refractory fingertip ulcerations in a patient with scleroderma: Successful treatment with sildenafil. J Rheumatol 2005;32:2440-2.

21. Francis SH, Corbin JD. Sildenafil: Efficacy, safety, tolerability and mechanism of action in treating erectile dysfunction. Expert Opin Drug Metab Toxicol 2005;1:283-93.

22. Hayreh SS. Erectile dysfunction drugs and non-arteritic anterior ischemic optic neuropathy: Is there a cause and effect relationship? J Neuroophthalmol 2005;25:295-8.

23. Laties AM. Vision disorders and phosphodiesterase type 5 inhibitors: A review of the evidence to date. Drug Saf 2009;32:1-18.

24. Kontaras K, Varnavas V, Kyriakides ZS. Does sildenafil cause myocardial infarction or sudden cardiac death? Am J Cardiovasc Drugs 2008;8:1-7.

25. Levien TL. Phosphodiesterase inhibitors in Raynaud's phenomenon. Ann Pharmacother 2006;40:1388-93.

26. Kamata Y, Kamimura T, Iwamoto M, Minota S. Comparable effects of sildenafil citrate and alprostadil on severe Raynaud's phenomenon in a patient with systemic sclerosis. Clin Exp Dermatol 2005;30:451.

27. Gore J, Silver R. Oral sildenafil for the treatment of Raynaud's phenomenon and digital ulcers secondary to systemic sclerosis. Ann Rheum Dis 2005;64:1387.

28. Baumhaekel M, Scheffler P, Boehm M. Use of tadalafil in a patient with a secondary Raynaud's phenomenon not responding to sildenafil. Microvasc Res 2005;69:178-9.

29. Kumana CR, Cheung GT, Lau CS. Severe digital ischaemia treated with phosphodiesterase inhibitors. Ann Rheum Dis 2004;63:1522-4.

30. Ulusoy MG, Uysal A, Kocer U, et al. Improved flap viability with site-specific delivery of sildenafil citrate using fibrin glue. Ann Plast Surg 2005;55:292-6.

31. Sarifakioglu N, Gokrem S, Ates L, Akbuga UB, Aslan G. The influence of sildenafil on random skin flap survival in rats: An experimental study. Br J Plast Surg 2004;57:769-72.

32. Tsai JW, Ayubi FS, Hart KL, et al. Evaluation of the effect of sildenafil and vascular endothelium growth factor combination treatment on skin flap survival in rats. Aesthetic Plast Surg 2008;32:624-31.

33. Hart K, Baur D, Hodam J, et al. Short- and long-term effects of sildenafil on skin flap survival in rats. Laryngoscop 2006;116:522-8.

34. Oh M, Chang H, Minn KW. The effects of tadalafil on axial-pattern skin flap survival in rats. Dermatol Surg 2008;34:626-30; discussion 630 . 